Introduction

\title{
Seaweed invasions: introduction and scope
}

\section{Craig R. Johnson ${ }^{1, *}$ and Anthony R.O. Chapman ${ }^{2}$}

${ }^{1}$ School of Zoology and Tasmanian Aquaculture and Fisheries Institute, University of Tasmania, GPO Box 252-05, Hobart, Tasmania 7001, Australia, e-mail: Craig.Johnson@utas.edu.au

${ }^{2}$ Department of Biology, Dalhousie University, Halifax, NS, Canada, B3H 4J1

* Corresponding author

\section{Background and motivation}

At no time in human history has the need to understand invasions of alien species - the process of invasion, impacts of invasion and meaningful options to respond to invasion - been so urgent. The rate of anthropogenically-mediated translocation of species to regions outside native ranges has never been greater. This is particularly true for marine species, among which it is estimated that, at any point in time, several thousand are being transported between biogeographic regions in ballast water alone (Carlton and Geller 1993, Carlton 1999). Furthermore, there is good evidence to suggest that in some areas establishment of alien marine species originating from hull fouling exceeds that attributable to transport in ballast water (Hewitt et al. 2004). Not surprisingly, the rate of establishment of alien marine species, including invasives, appears to be increasing (e.g., Cohen and Carlton 1998, Ruiz et al. 2000), and some marine bays realise a newly established species every 30-40 weeks (Hewitt 2003). These trends are evident in marine, freshwater and terrestrial environments alike, and have raised considerable angst about the ecological, economic and social consequences (e.g., Pimentel et al. 1999, Mack et al. 2000, Sala et al. 2000, Lodge 2001, Bax et al. 2003).

Seaweeds are a significant component of those marine organisms that have established as alien species in new bioregions, in some regions comprising $\sim 5 \%$ of the total flora (Ribera and Boudouresque 1995) and $\sim 10-40 \%$ of the total alien species (Schaffelke et al. 2006), and several species have been invasive (e.g., Nyberg and Wallentius 2005, this special issue). However, as is the case in studying many other kinds of invasive marine species (Grosholz 2002), investigation of the seaweed component has been dominated by case studies that are often strongly idiographic, focusing on high profile taxa that have, or might have, large ecological or economic effects. There has been little attempt to synthesise this body of work, either in the context of seaweed biology and ecology or more general invasion ecological theory. Our intention here is to go beyond the case studies and the sui generis in search of patterns and commonalities. Of course, the case studies must be included for reference, for they comprise the knowledge base on the species and communities invaded.

A deep understanding of the invasion process, impacts and options to manage invasions can only come from integrating observation of natural systems across a variety of scales with results of controlled experiments, and with ecological theory. A lack of integration of this kind and a focus on case studies and particular invasion events is arguably part of the reason for the historical disconnection between invasion ecology and mainstream ecological theory (Davis et al. 2001, see also Cadotte 2006). Notwithstanding Davis' (2006) harsh criticism that there has been little change in the questions and answers about invasion ecology in four decades, we suggest that recent syntheses working towards a confluence of survey, experiment and theory have contributed important advances in the understanding of invasions (e.g., Levine and D'Antonio 1999, Shea and Chesson 2002, Bruno et al. 2005, Stachowicz and Tilman 2005, Fridley et al. 2007). It is now both opportune and necessary to attempt to consider invasive seaweeds in this concourse.

Deep understanding also requires critical analysis of data and evidence. This sounds self-evident, but several authors have pointed out that, for example, putative claims of the impacts of alien invasive species are often unsupported by data or critical analysis (Gurevitch and Padilla 2004, Didham et al. 2005, MacDougall and Turkington 2005), and a recent review concludes there is little evidence that many alien invasive species cause the impacts and problems attributed to them (Bruno et al. 2005). While it is clear that some invasive marine species do have large impacts on the structure and dynamics of the systems in which they proliferate (e.g., Nichols et al. 1990, Carlton 1996, Shiganova 1998, Daskalov 2002, 2003, Ross et al. 2003), this review provides an opportunity to carefully examine available evidence of invasion processes and impacts for invasive seaweeds.

The overall aim of this collection is thus to synthesise current information about invasive seaweeds and human responses to them, and attempt to consider seaweed invasions in the context of a broader thinking about invasion ecology. We consider the means, both accidental and intentional, by which seaweeds are introduced to new biogeographic domains, mechanisms of their invasion and impact, and practical approaches to tracking and controlling seaweed invasions. Because practical responses to seaweed invasions invariably take place within a regulatory framework, a review of legal and policy responses is also included as a fundamental element of the interaction between society and invasive seaweeds. Inevitably, this work is also about identifying gaps, and, therefore, challenges and priorities for the future. 
Important questions that are not unique to seaweed invasions provide a structure for examining whether generalisations can be drawn from the case studies, and these questions have framed the approach to this topic. They include:

- What are the major modes of introduction of invasive seaweeds?

- Is there tangible pressure for ongoing intentional introductions?

- What are sensible approaches to reducing risk of further introductions?

- Is it possible to predict the "next pest" seaweed?

- Are there common life-history or genetic traits of successful invaders?

- Why do some species become invasive while others do not?

- Are there common mechanisms underpinning seaweed invasions?

- Why do some communities appear to be more susceptible to invasion than others? Do the traits of the recipient community influence invasion rates?

- How have seaweed invasions been tracked, and can existing approaches be improved?

- Is it possible to predict the course of an invasion?

- What are the ecological, genetic and economic consequences of seaweed invasions?

- Can we expect that existing and, in particular, emerging techniques in genetics and genomics will provide a much deeper understanding of seaweed invasions?

- How should humans respond to seaweed invasions?

- Is the global regulatory framework in which responses to actual and potential seaweed invasions are determined adequate?

We do not expect all of these questions to be answered with equal conviction, but we should be sanguine in establishing them as useful, if only to identify important areas of deficit in knowledge. The approach to these questions by most of the authors is strongly empirical, although the interface of some of these issues with ecological theory is considered where appropriate. Dunstan and Johnson (2007) in particular address the question of the properties of receiving communities in influencing invasion rates from a theoretical perspective, in part because of the dearth of meaningful empirical observations that contribute to the issue. Indeed, the extent of empirical knowledge of seaweed invasions is limited and highly skewed towards particular species. For example, 260 or so alien seaweed species have been identified (Schaffelke et al. 2006) but for only 17 have ecological impacts been considered at all and, arguably, for only four is there a solid empirical and experimental basis (Schaffelke and Hewitt 2007). Thus, we recognise that this synthesis, driven by questions relevant to applied and theoretical ecology, may be evanescent. Nonetheless it is overdue.

\section{Modes of introduction}

In recognising that $<3 \%$ of introductions of alien seaweed species are intentional, Hewitt et al. (2007) focus on reviewing modes of accidental introductions and identify hull fouling as the most significant, but also the most poorly managed, transport mechanism for seaweeds. They emphasise that while eliminating risk is rarely possible, there are several options for risk mitigation. They also address the challenge of identifying potential "next pests", and argue that this is best tackled based on assessment of risk at the three main stages of the invasion process (uptake and transport, establishment, spread) and not on particular properties of species. Later in the issue, Valentine et al. (2007) corroborate this stance in concluding that there is no evidence of a common suite of traits of invasive seaweeds, in line with suggestions two decades ago (e.g., Crawley 1987).

But there is also pressure for further intentional introductions. This is driven by ongoing demand for seaweeds and their products, and perceptions that seaweed based industry offers an alternative and sustainable livelihood to coastal populations, particularly in developing nations (Pickering et al. 2007). Only a small number of seaweed species have been introduced intentionally, and rarely have these become particularly problematic [the introduction of Undaria pinnatifida (Harvey) Suringar in Brittany may be a notable exception]. Importantly however, Pickering et al. (op. cit.) find that intentionally introduced seaweeds are no more or less risk prone than unintentionally introduced seaweeds. Not surprisingly then, they too consider a careful risk assessment essential when there are plans to introduce species for aquaculture purposes. Clearly, species being considered for aquaculture should not be on watch lists of invasive species maintained by government agencies, NGOs or intergovernmental organizations, or figure prominently in scientific literature on invasive seaweeds. Moreover, as Pickering et al. (op. cit.) acknowledge, impacts realised in one area may not be good at predicting those in another (see also Grosholz 1996, Schaffelke and Hewitt 2007). Another risk is that intentionally introduced specimens may harbour "hitchhikers", a problem that can only be dealt with by proper quarantine procedures. Notably, there are only two published reports of quarantining seaweeds.

\section{Mechanisms of invasion and tracking invasions}

In addressing mechanisms of invasion (Dunstan and Johnson 2007, Valentine et al. 2007), it is useful to consider why some species become invasive while others do not. For example, of the many taxa of the genus Codium off Japan, only one has become a worldwide pest [Codium fragile ssp. tomentosoides (van Goor) P.C. Silva; Trowbridge 1998]. Historically, seaweed ecologists sought explanations for species occurrences in physiological attributes. Species tolerances to light, temperature and salinity, for example, were thought to explain patterns seen in nature (reviewed by Lüning 1990), although by the 1970 s interactions among species (e.g., competition, predation, facilitation) were recognised as major structuring agents of seaweed communities (Chapman 1986). In the same way, the first studies of invasive seaweeds concentrated on properties of the 
invaders in predicting consequences of introduction at new sites, sometimes with disastrous consequences as occurred with the introduction of Undaria pinnatifida in Brittany (Meinesz 2007). However, as outlined earlier, Valentine et al. (2007) show that life history characteristics are of little value in predicting invasion. Rather they show that, in many cases, disturbances to native assemblages free resources and pave the way for alien species to establish at high densities. These facilitative disturbances may be grazers, storms or other invasive species. In Tasmania, for example, disturbance patterns can account for observations that some patches are invaded by Undaria pinnatifida at high densities (Valentine and Johnson 2003, 2004) while others nearby are not.

Invasion patterns are also highly variable at much larger spatial scales. Codium fragile ssp. tomentosoides does not reach nuisance proportions in all of the communities in which it has been introduced. This subspecies is quite rare in subtidal waters of the eastern North Atlantic Ocean, whereas it forms meadows that can replace kelp forests in the western Atlantic Ocean (Chapman et al. 2002). In fact several species that are invasive elsewhere in the world are not pests in their native communities (Trowbridge 1998). These observations suggest that properties of the invaded community also determine the success of the invader. This topic is explored by both Valentine et al. (2007) and Dunstan and Johnson (2007), who suggest that this kind of variability can be explained by patterns of differential resource availability. Dunstan and Johnson's (op. cit.) work is largely theoretical, but they argue that seaweed communities, which often manifest a dynamic mosaic of patches in space and time, have properties likely to show stronger responses to resource variability than to species richness or diversity of the recipient community per se.

Means of tracking seaweed invasions have, on the whole, been notable for the simplicity of the technologies employed, with the possible exception of some kinds of remote sensing (Meinesz 2007). Exotic species have been tracked along the coasts of several countries, and these positive results have underscored the importance of public education programs and community involvement in initial detection. Indeed, the first occurrence of Caulerpa taxifolia (M. Vahl) C. Agardh in Tunisia was reported by a fisherman responding to a public awareness campaign that distributed 300,000 brochures across eight Mediterranean countries. Cartographical data from an informed public, along with expert sampling, has allowed tracking of the invasion pathways of two Caulerpa species. Sophisticated genetic techniques can potentially be helpful in tracking invasions, but have largely been employed, with considerable success, in identifying the initial source(s) of invasions, including cryptic ones (Booth et al. 2007).

\section{Consequences of invasions}

Schaffelke and Hewitt (2007) review the ecological impacts of seaweeds on recipient communities. They catalogue a variety of impacts, but they also emphasise the limited scope of extant work, which covers remark- ably few of the total number of known alien seaweed species, and as few as four invasive species in any detail. With the exception of studies in Tasmania (on Undaria pinnatifida), Nova Scotia (on Codium fragile ssp. tomentosoides) and Tuscany (on two invasive Caulerpa species co-existing with two introduced red turfing algae from Australia), there have been few comprehensive experimental works on seaweed invasion ecology. In most cases the mechanisms of observed ecological effects are unknown (Schaffelke et al. op. cit.). However, even the relatively limited amount of work to date shows that a given species might have very different impacts in different locales. Along with the rather limited information on ecological impacts, Schaffelke et al. (op. cit.) point out that there is surprisingly little known of economic impacts of seaweed invasions. Nevertheless, applied science studies have received government funding, resulting in considerable research effort, for example, in the Mediterranean Sea.

There are even fewer studies of genetic consequences of invasive seaweeds, with most genetic investigations focusing on identifying source populations (Booth et al. 2007). The work that has been done reveals the complexity of underlying colonisation patterns and genetic impacts, which Booth et al. (op. cit.) categorise broadly as changes in population genetic structure and changes in genomic structure, for example, through hybridisation. In one example, molecular analyses revealed considerable genetic diversity within invader populations of Undaria pinnatifida, probably reflecting multiple introductions from different sources. This species is a vigorous invader, first found outside its native Japanese range in the Mediterranean Sea in 1971 (Meinesz 2007), but with subsequent invasion of the northeastern Atlantic Ocean, New Zealand, Australia, Argentina and the northeastern Pacific Ocean. However, it seems that its vigour as an invader cannot be related to its genetic diversity, in part because most of the other successful invasive seaweeds have experienced genetic bottlenecks and manifest greatly reduced genetic variation. Indeed, the highly invasive strain of Caulerpa taxifolia consists of male thalli that reproduce vegetatively. Clearly, invasive virulence does not depend on genetic diversification. At a genomic level, there is only a single unequivocal example of hybridisation involving an invasive seaweed. Fucus evanescens C. Agardh was introduced to the Oslofjord but it migrated south into the Baltic Sea where it hybridised with F. serratus L.; interestingly, the hybrids occur in a restricted hybrid zone on the shore. Although hybridisation involving invasive seaweeds is likely to be rare, the future for genomic-level research is nonetheless a bright one, with the prospect of revealing adaptive traits and genotypephenotype-environment interactions (Booth et al. 2007).

\section{Human responses to seaweed invasions}

Unfortunately, about $97 \%$ of seaweed incursions are accidental (Hewitt et al. 2007) and usually occur in regions not subject to monitoring, so they escape early detection. In these cases, eradication is not likely to be successful and management measures may need to be 
invoked. However, efforts to manage invasive seaweed populations have not been very successful (Anderson 2007), in part because of the massive reproductive potential of many seaweeds (e.g., Chapman 1984, Schaffelke et al. 2005) and their capacity for relatively long distance dispersal (Reed et al. 1988, Kinlan and Gaines 2003). In contrast, the few eradication programs that aimed to completely extirpate an invader population have been highly successful, as occurred in response to invasion of the California coast by Caulerpa taxifolia and Ascophyllum nodosum (L.) Le Jolis (Anderson 2007). Success stories like this are rare because of long latency periods during which detection can be difficult, and because they are expensive. Even when an invasion is discovered early, immediate, coordinated and massive action using highly developed methodologies is usually necessary, and even the sampling design to detect every single invading individual usually requires research development effort. Nonetheless, eradication in concert with early detection emerges as a cost effective response (Anderson op. cit.).

No consideration of human responses to invasive species would be complete without consideration of the regulatory environment that defines limits to movement, use and handling of alien species and, in some cases, responses to invasive aliens. Ultimately it is governments that determine responses to invasive species, not scientists or environmental agencies, but coordination among governments at a global scale is poor. For example, only Australia, New Zealand, USA, Canada, Switzerland and Germany have legislation controlling introductions for aquaculture. This legislation has developed from both global and regional policies including the Law of Sea, the Convention on Biodiversity, the International Convention on Wetlands, and the Convention on Migratory Species of Wild Animals (Doelle et al. 2007). These policies have led to global initiatives such as the development of a Code of Conduct for Responsible Fisheries by the Food and Agriculture Organization. The International Maritime Organisation recognises ships' ballast water as a major vector for invasives, and there are guidelines for handling waste water and sediment in ships. However, fouling of ship hulls is a much more important vector for seaweeds than ballast, and changes in the composition of anti-fouling substances on ships' hulls (mandated by the International Convention on Control of Harmful Anti-Fouling systems on Ships) will promote increased fouling by seaweeds as the use of toxic compounds in antifoulants such as tributyltin (TBT) are phased out. Importantly, none of the international conventions is self-implementing, even those issued by a close-knit political alliance like the European Union, and so national legislation and enforcement are required. Australia and New Zealand have taken this more seriously than other nation states but, in general, the development of effective legal and policy responses to invasive seaweeds is fragmented at both regional and global levels, and at an early stage of development (Doelle et al. op. cit.).

In the end, control of seaweed or any other invasions should be a component of an integrated multi-faceted approach dealing with all problems in the marine envi- ronment including, for example, overfishing, climate change, marine debris and habitat modification. Doelle et al. (op. cit.) point out that there are a raft of powerful regulatory tools available to employ, but there is yet a great deal to do. It will not be possible to turn the clock back 500 years to the more pristine conditions that once existed, but it is necessary, at least, to stop things getting worse.

\section{References}

Anderson, L.W.J. 2007. Control of invasive seaweeds. Bot. Mar. 50: 418-437.

Bax, N., A. Williamson, M. Aguero, E. Gonzalez and W. Geeves. 2003. Marine invasive alien species: a threat to global biodiversity. Mar. Policy 27: 313-323.

Booth, D., J. Provan and C.A. Maggs. 2007. Molecular approaches to the study of invasive seaweeds. Bot. Mar. 50: 385-396.

Bruno, J.F., J.D. Fridley, K.D. Bromberg and M.D. Bertness. 2005. Insights into biotic interactions from studies of species invasions. In: (D.F. Sax, J.J. Stachowicz and S.D. Gaines, eds) Species invasions: insights into ecology, evolution and biogeography. Sinauer Associates, Sunderland. pp. 13-40.

Cadotte, M.W. 2006. Darwin to Elton: early ecology and the problem of invasive species. In: (M.W. Cadotte, S.M. McMahon and T. Fukami, eds) Conceptual ecology and invasion biology: reciprocal approaches to nature. Springer, Dordrecht. pp. 15-33.

Carlton, J.T. 1996. Marine bioinvasions: the alteration of marine ecosystems by nonindigenous species. Oceanography 9: 36-43.

Carlton, J.T. 1999. The scale and ecological consequences of biological invasions in the world's oceans. In: (O.T. Sandlund, P.J. Schei and $\AA$. Viken, eds) Invasive species and biodiversity management. Kluwer Academic Publishers, Dordrecht. pp. 195-212.

Carlton, J.T. and B.J. Geller. 1993. Ecological roulette: the global transport of nonindigenous marine organisms. Science 261: 79-82.

Chapman, A.R.O. 1984. Reproduction, recruitment and mortality in two species of Laminaria in southwest Nova Scotia. J. Exp. Mar. Biol. Ecol. 78: 99-109.

Chapman, A.R.O. 1986. Population and community ecology of seaweeds. Adv. Mar. Biol. 23: 1-161.

Chapman, A.S., R.E. Scheibling and A.R.O. Chapman. 2002. Species invasions and changes in marine vegetation of Atlantic Canada. In: (R. Claudi, ed.) Alien invasive species: threats to Canadian biodiversity. Natural Resources Canada, Ottawa. pp. 133-148.

Cohen, A.N. and J.T. Carlton. 1998. Accelerating invasion rate in a highly invaded estuary. Science 279: 555-558.

Crawley, M.J. 1987. What makes a community invasible? In: (A.J. Gray, M.J. Crawley and P.J. Edwards, eds) Colonization, succession and stability. Blackwell Scientific, Oxford. pp. 429-453.

Daskalov, G.M. 2002. Overfishing drives a trophic cascade in the Black Sea. Mar. Ecol. Prog. Ser. 225: 53-63.

Daskalov, G.M. 2003. Long-term changes in fish abundance and environmental indices in the Black Sea. Mar. Ecol. Prog. Ser. 255: 259-270.

Davis, M.A. 2006. Invasion biology 1958-2005: the pursuit of science and conservation. In: (M.W. Cadotte, S.M. McMahon and T. Fukami, eds) Conceptual ecology and invasion biology: reciprocal approaches to nature. Springer, Dordrecht. pp. 35-64.

Davis, M.A., K. Thompson and J.P. Grime. 2001. Charles S. Elton and the dissociation of invasion ecology from the rest of ecology. Divers. Distrib. 7: 97-102. 
Didham, R.K., J.M. Tylianakis, M.A. Hutchinson, R.E. Ewers and N.J. Gemmel. 2005. Are invasive species the drivers of ecological change? Trends Ecol. Evol. 20: 470-474.

Doelle, M., M.L. McConnell and D.L. VanderZwaag. 2007. Invasive seaweeds: global and regional law and policy responses. Bot. Mar. 50: 438-450.

Dunstan, P.K. and C.R. Johnson. 2007. Mechanisms of invasion: can the recipient community influence invasion rates? Bot. Mar. 50: 361-372.

Fridley, J.D., J.J. Stachowicz, S. Naeem, D.F. Sax, E.W. Seabloom, M.D. Smith, T.J. Stohlgren, D. Tilman and B. Von Holle. 2007. The invasion paradox: reconciling pattern and process in species invasions. Ecology 88: 3-17.

Grosholz, E.D. 1996. Contrasting rates of spread for introduced species in terrestrial and marine systems. Ecology 77: 1680-1686.

Grosholz, E.D. 2002. Ecological and evolutionary consequences of coastal invasions. Trends Ecol. Evol. 17: 22-27.

Gurevitch, J. and D.K. Padilla. 2004. Are invasive species a major cause of extinctions? Trends Ecol. Evol. 19: 470-474.

Hewitt, C.L. 2003. Marine biosecurity issues in the world oceans: global activities and Australian directions. Ocean Yearbook 17: 193-212.

Hewitt, C.L., M.L. Campbell, R.E. Thresher, R.B. Martin, S. Boyd, B.F. Cohen, et al. 2004. Introduced and cryptogenic species in Port Phillip Bay, Victoria, Australia. Mar. Biol. 144: 183-202.

Hewitt, C.L., M.L. Campbell and B. Schaffelke. 2007. Introductions of seaweeds: accidental transfer pathways and mechanisms. Bot. Mar. 50: 326-337.

Kinlan, B.P. and S.D. Gaines. 2003. Propagule dispersal in marine and terrestrial environments: a community perspective. Ecology 84: 2007-2020.

Levine, J.M. and C.M. D'Antonio. 1999. Elton revisited: a review of evidence linking diversity and invasibility. Oikos 87: 15-26.

Lodge, D.M. 2001. Lakes. In: (F.S. Chapin, O.E. Sala and E. Huber-Sannwald, eds) Future scenarios of global biodiversity. Springer-Verlag, New York. pp. 277-312.

Lüning, K. 1990. Seaweeds. Their enivironment, biogeography and ecophysiology. Wiley, New York. pp. 527.

MacDougall, A.S. and R. Turkington. 2005. Are invasive species the drivers or passengers of change in degraded ecosystems? Ecology 86: 42-55.

Mack, R.N., D. Simberloff, W.M. Lonsdale, H. Evans, M. Clout and F.A. Bazzaz. 2000. Biotic invasions: causes, epidemiology, global consequences, and control. Ecol. Appl. 10: 689-710.

Meinesz, A. 2007. Methods for identifying and tracking seaweed invasions. Bot. Mar. 50: 373-384.

Nichols, F.H., J.K. Thompson and L.E. Schemel. 1990. Remarkable invasion of San Francisco Bay (California, USA) by the Asian clam Potamocorbula amurensis. II. Displacement of a former community. Mar. Ecol. Prog. Ser. 66: 95-101.

Nyberg, C.D. and I. Wallentius. 2005. Can species traits be used to predict marine macroalgal introductions? Biol. Invasions 7 : 265-279.
Pickering, T.D., P. Skelton and R.J. Sulu. 2007. Intentional introductions of commercially harvested alien seaweeds. Bot. Mar. 50: 338-350.

Pimentel, D., L. Lach, R. Zuniga and D. Morrison. 1999. Environmental and economic costs of nonindigenous species in the United States. Bioscience 50: 53-65.

Reed, D.C., D.R. Laur and A.W. Ebeling. 1988. Variation in algal dispersal and recruitment: the importance of episodic events. Ecol. Monogr. 58: 321-335.

Ross, D.J., C.R. Johnson and C.L. Hewitt. 2003. Assessing the ecological impacts of an introduced seastar: the importance of multiple methods. Biol. Invasions 5: 3-21.

Ribera, M.A. and C.-F. Boudouresque. 1995. Introduced marine plants, with special reference to macroalgae: mechanisms and impact. Prog. Phycol. Res. 11: 187-268.

Ruiz, G.M., P. Fofonoff, J.T. Carlton, M.J. Wonham and A.H. Hines. 2000. Invasions of coastal marine communities in North America: apparent patterns, processes and biases. Annu. Rev. Ecol. Syst. 31: 481-531.

Sala, O.E., F.S. Chapin III, J.J. Armesto, E. Berlow, J. Bloomfield, R. Dirzo, et al. 2000. Biodiversity scenarios for the year 2100 . Science 287: 1770-1774.

Schaffelke, B. and C.L. Hewitt. 2007. Impacts of introduced seaweeds. Bot. Mar. 50: 397-417.

Schaffelke, B., M.L. Campbell and C.L. Hewitt. 2005. Reproductive phenology of the introduced kelp Undaria pinnatifida (Phaeophyceae, Laminariales) in Tasmania, Australia. Phycologia 44: 84-94.

Schaffelke, B., J.E. Smith and C.L. Hewitt. 2006. Introduced macroalgae - a growing concern. J. Appl. Phycol. 18: 529-541.

Shea, K. and P. Chesson. 2002. Community ecology theory as a framework for biological invasions. Trends Ecol. Evol. 17: 170-176.

Shiganova, T.A. 1998. Invasion of the Black Sea by the ctenophore Mnemiopsis leidyi and recent changes in pelagic community structure. Fish. Oceanogr. 7: 305-310.

Stachowicz, J.J. and D. Tilman. 2005. Species invasions and the relationships between species diversity, community saturation, and ecosystem functioning. In: (D.F. Sax, J.J. Stachowicz and S.D. Gaines, eds) Species invasions: insights into ecology, evolution and biogeography. Sinauer Associates, Sunderland. pp. 41-64.

Trowbridge, C. 1998. Ecology of the green macroalga Codium fragile (Suringar) Hariot 1889: invasive and non-invasive subspecies. Oceanogr. Mar. Biol. Ann. Rev. 36: 1-65.

Valentine, J.P. and C.R. Johnson. 2003. Establishment of the introduced kelp Undaria pinnatifida in Tasmania depends on disturbance to native algal assemblages. J. Exp. Mar. Biol. Ecol. 295: 63-90.

Valentine, J.P. and C.R. Johnson. 2004. Establishment of the introduced kelp Undaria pinnatifida following dieback of the native macroalga Phyllospora comosa in Tasmania, Australia. Mar. Freshw. Res. 55: 223-230.

Valentine, J.P., R.H. Magierowski and C.R. Johnson. 2007. Mechanisms of invasion: establishment, spread and persistence of introduced seaweed populations. Bot. Mar. 50: 351360 